\title{
Control of Cellular Proliferation in the Bovine Cornea: An in vitro Study
}

\author{
T. J. C. JACOB, S. CRUWYS and 'I. A. MACKIE \\ London
}

\begin{abstract}
Summary
Keratocytes from the bovine cornea secrete a factor(s) that stimulates the proliferation of corneal epithelial cells. The novel finding of this study is that this stimulation was only achieved if the epithelial cells were already proliferating. Cells which had stopped growing could not be stimulated to re-enter the growth cycle. This stimulation was not reciprocal; the growth of keratocytes was not stimulated by factor(s) secreted by the epithelium, whereas epithelial factors were able to stimulate the proliferation of thermocytes.

The importance of these non-reciprocal growth responses to corneal wound healing and immune response is discussed.
\end{abstract}

Stromal keratocytes from the rabbit cornea secrete a diffusible factor that stimulates the proliferation of corneal epithelial cells. ${ }^{1}$ Since the rate of proliferation of epithelial cells increases greatly after wounding, and has been shown to be a biphasic process, ${ }^{2}$ we were interested in determining the effect of keratocyte-derived factors on epithelial cells during the different phases of the cell cycle. It has also been reported that corneal epithelial cells secrete a thymocyte activating factor ${ }^{3}$ but it is not known whether the keratocytederived factor(s) also activates thymocytes. This study, therefore, sets out to investigate the reciprocity of growth factors produced by corneal keratocytes and epithelial cells.

\section{Materials and Methods}

Preparation of Cultures

Bovine eyes were obtained from a local abat- toir and used $\leqslant 4$ hours post mortem. The front of the eye was gently scraped with a sterile scalpel to remove mucous and debris. The globe was bisected just anterior to the ora serrata and the lens and ciliary body removed. Each anterior section of six eyes, consisting of the cornea with a rim of sclera, was then taken through three washes of Dulbecco's phosphate buffered saline (DPBS) with antibiotics $(250 \mathrm{U} / \mathrm{ml}$ penicillin; $250 \mu \mathrm{g} / \mathrm{ml}$ streptomycin; $100 \mu \mathrm{g} / \mathrm{ml}$ gentamycin) and antimycotics (7.5 $\mu \mathrm{g} / \mathrm{ml}$ amphotericin B). Each cornea was placed, anterior side uppermost, on a cylindrical mount and the centre depressed to form a hollow. A sequential digestion technique was used to obtain cells from different corneal layers. Trypsin-EDTA solution; $0.1 \%$ trypsin type IIIs (Sigma, Poole, UK), 0.02\% EDTA, $5 \mathrm{mM}$ glucose in phosphate buffered saline (PBS) without calcium or magnesium was placed onto the cornea and the preparation

From: Department of Pharmacology, St. George's Hospital Medical School, Cranmer Terrace, London SW17 0RE.

'Eye Department, Lanesborough Wing, St. George's Hospital, London SW17 0QT.

Correspondence to: T. J. C. Jacob, Physiology Department, University of Wales, College of Cardiff, PO Box 902, Cardiff CF1 1SS. 
was incubated at $37^{\circ} \mathrm{C}$ for 30 minutes. After trituration with a sterile pasteur pipette the first digest was removed and discarded. The subsequent digests, taken at 30 minute intervals, were placed in an equivolume of a trypsin inhibitor solution containing DNase $(0.1 \%$ soya bean trypsin inhibitor type Is (Sigma), 50 $\mu \mathrm{g} / \mathrm{ml}$ DNAase, $0.3 \%$ bovine serum albumen, $3 \mathrm{mM} \mathrm{Mg}^{2+}, 5 \mathrm{mM}$ glucose in PBS). The solution was triturated to break up clumps, centrifuged $(1,000 \mathrm{rpm}$ for $5 \mathrm{~min})$ and resuspended in the wash solution (DPBS with antibiotics and antimycotics). This procedure was repeated twice and the cells were finally resuspended in growth medium (DMEM) with $10 \%$ fetal calf serum (FCS), counted on a haemocytometer and plated out on collagen (type I, Sigma)-coated flasks at $2 \times 10^{4}$ cells/ $\mathrm{cm}^{2}$. In primary culture the cells generally took between four to seven days to adhere to the substrate and thereafter grew to confluence rapidly (within a further seven days). Cells from the second and third digests (60 and 90 min respectively) produced pure epi- thelial cultures (Fig. 1a); cells from the fourth digest $(120 \mathrm{~min})$ were a mixture of epithelial cells of a more polymorphous phenotype and stromal keratocytes, while the fifth digest $(150$ min) generally produced keratocytes which overgrew any epithelial cells present (Fig. 1b).

\section{Growth Assays}

Cells from confluent cultures were removed from the flasks by trypsinisation. After centrifugation (1,000 rpm for five minutes) the cells were resuspended in DMEM $+10 \%$ FCS and counted on a haemocytometer. The suspension was then diluted to the appropriate concentration. During seeding the cells were maintained in suspension by vortex mixing. This guaranteed a uniform seeding density. The cells were pipetted into collagen-coated multiwell plates and placed in a gassed $(5 \%$ $\mathrm{CO}_{2}$ ), humidified incubator at $37^{\circ} \mathrm{C}$. After 24 hours the medium was changed and the number of adherent cells was counted. The cells were therefore exposed to the relevant

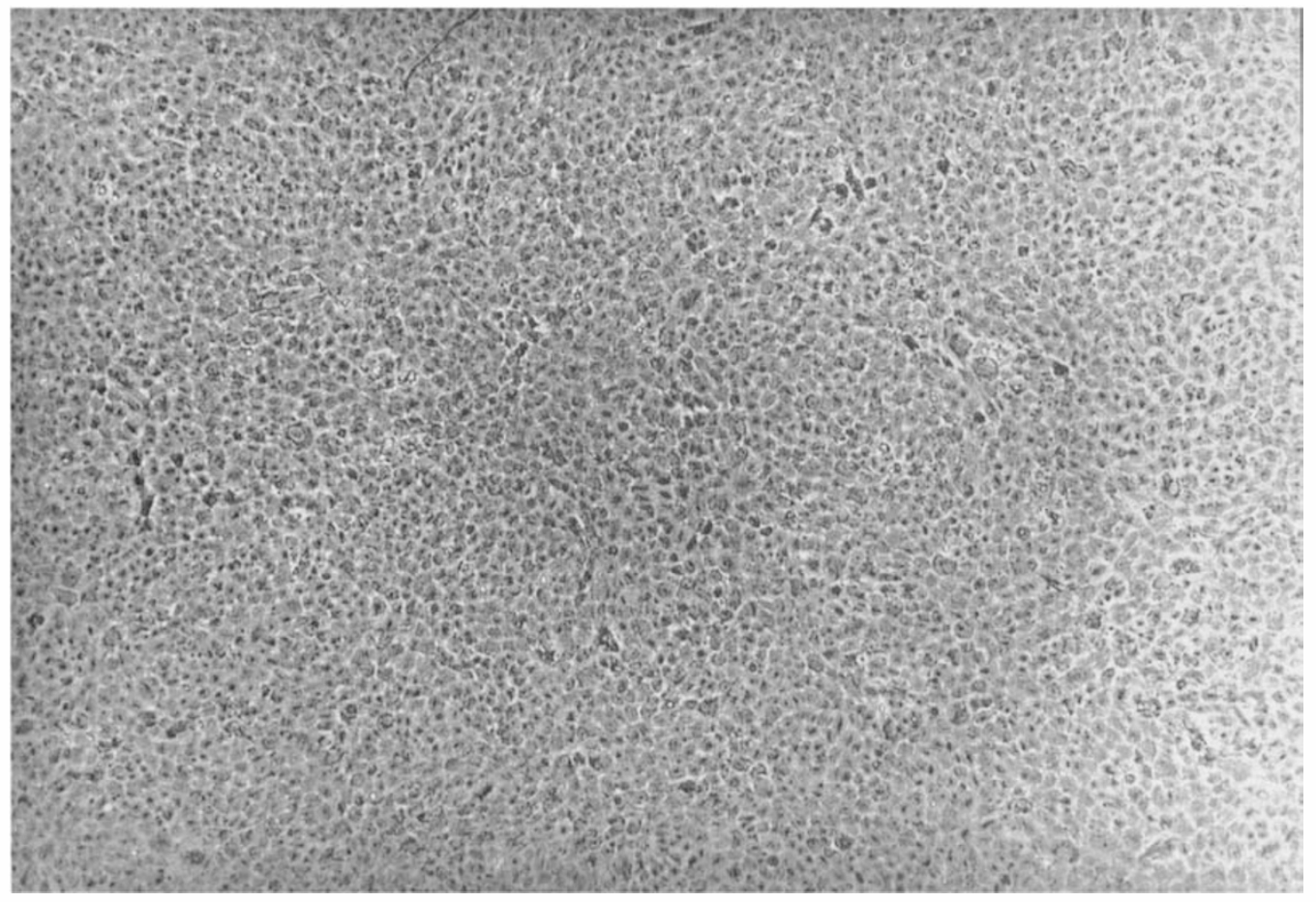

Fig. 1a. Cultured bovine corneal epithelial cells. These cells were isolated from the front of the cornea by serial enzymatic digestion (see Materials and Methods). Phase contrast microscopy, field width $1.1 \mathrm{~mm}$. 


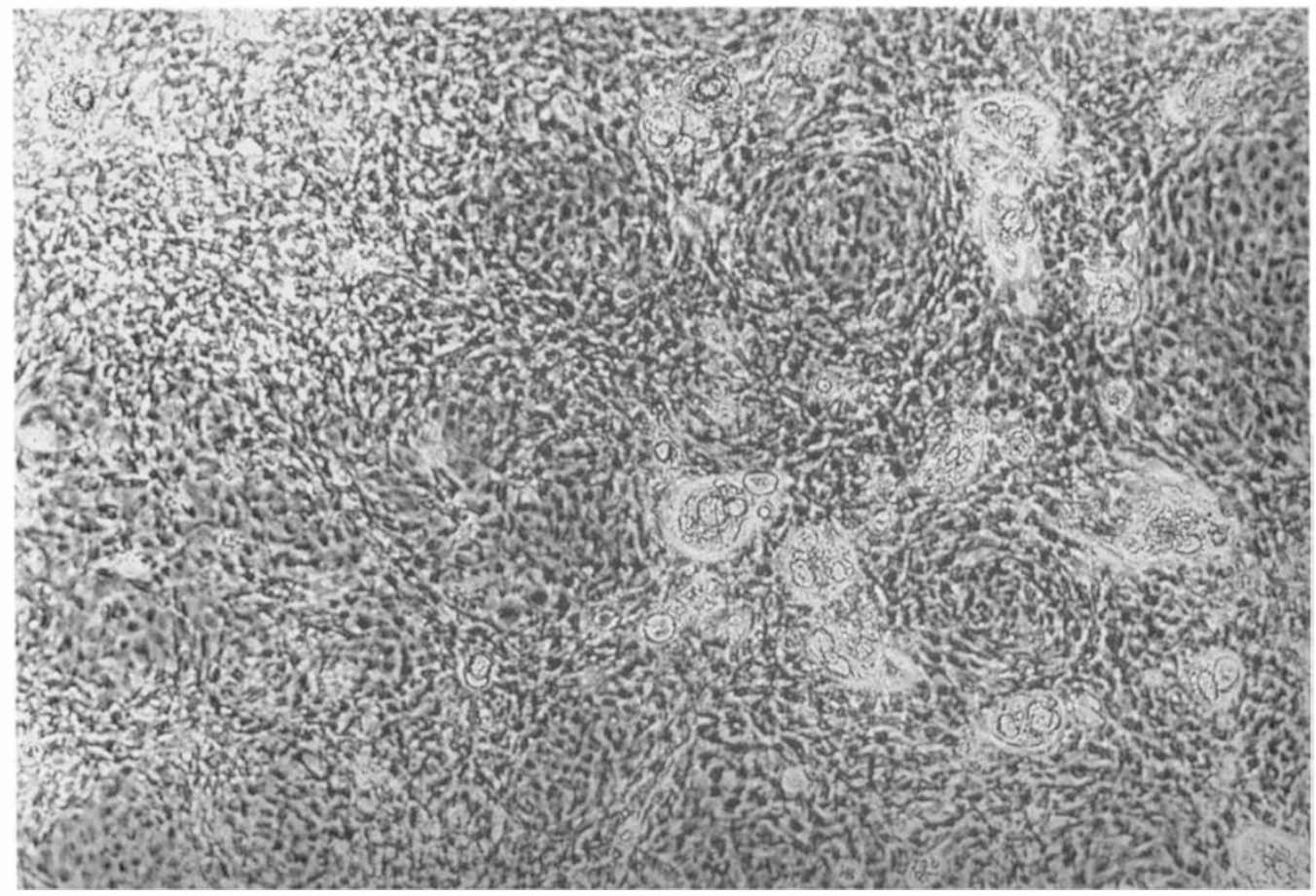

Fig. 1b. Cultured bovine corneal keratocytes. These cells were isolated by the serial enzymatic digestion technique referred to above. Phase contrast microscopy. Field width $1.1 \mathrm{~mm}$.

conditions after plating down thus avoiding the possible effects on plating efficiency. This count formed the initial population number $\mathrm{N}_{\mathrm{o}}$. All cell counts represent the mean ( \pm standard error) of triplicate cultures.

\section{Gompertz Growth Function}

In order to quantify cellular proliferation the Gompertz growth function (equation 1) was fitted to the data:

$$
\mathrm{N}_{\mathrm{t}}=\mathrm{N}_{\mathrm{o}} \cdot \exp \{\mathrm{A} / \mathrm{r}[1-\exp (-\mathrm{r} . \mathrm{t})]\}
$$

where $N_{t}=$ number of cells at time $t$, $\mathrm{N}_{\mathrm{o}}=$ initial number of cells,

$\mathrm{A}=$ growth rate constant and $\mathrm{r}=$ retardation constant.

At $\mathrm{t} \rightarrow \infty$ this simplifies to:

$$
\mathrm{N}_{\mathrm{t}} / \mathrm{N}_{\mathrm{o}}=\exp (\mathrm{A} / \mathrm{r})
$$

and from this it follows that the maximum number of population doublings is:

$$
\mathrm{PDL}_{\text {max }}=(\mathrm{A} / \mathrm{r}) / \log _{\mathrm{e}} 2
$$

An iterative algorithm for minimising the sum of the square of the residuals was used to obtain the best fit of equation 1 to the data with $\mathrm{A}$ and $\mathrm{r}$ as the variable parameters. The maximum population doubling level was calculated by inserting these values into equation 3. In this manner absolute values of the growth parameters could be compared between cultures exposed to different culture conditions. This approach has been extensively used in both normal and neoplastic growth in many types of tissue. ${ }^{4-8}$

\section{Conditioned Medium}

Bovine corneal keratocyte conditioned medium. The medium was removed from confluent cultures of bovine corneal keratocytes. The cultures were washed twice with DPBS to remove all trace of serum. and placed in DMEM containing insulin $(25 \mu \mathrm{g} / \mathrm{ml})$ and transferrin $(5 \mu \mathrm{g} / \mathrm{ml})$. This serum-free medium is referred to as DMEIT. The cultures were incubated in DMEIT for two days, whereupon the medium was withdrawn, filtered $(0.2 \mu \mathrm{m})$ and frozen $\left(-20^{\circ} \mathrm{C}\right)$. 
Bovine corneal epithelial cell conditioned medium. Medium was removed from confluent cultures of bovine corneal epithelial cells. The cultures were washed twice as above and the medium replaced by DMEIT. After two days the medium was withdrawn, filtered and frozen. It was found that epithelial cells could be maintained in this serumfree medium but would not undergo more than one division cycle (Cruwys and Jacob, unpublished data).

\section{Thymocyte Assay}

An assay based on that described by Luger $e t$ $a l .{ }^{9}$ was used. Briefly, single cell suspensions of mouse thymocytes were prepared by gently pressing the thymus through a nylon gauze. The cells were washed once and resuspended at $1.5 \times 10^{7}$ cells $/ \mathrm{ml}$ in complete RPMI medium. Thymocytes were cultured for 72 hours at $1.5 \times 10^{6}$ cells/well in tissue culture plates with 96 flat bottom wells in the presence and absence of concanavalin $\mathrm{A}(1 \mu \mathrm{g} / \mathrm{ml})$ and various dilutions of conditioned medium. Cultures were pulsed with $0.5 \mu \mathrm{Ci}{ }^{3} \mathrm{H}$-thymidine per well $(2 \mathrm{Ci} / \mathrm{mM}$, Amersham, UK) for the final 6 hours of incubation. Cells were collected on filter paper with a Millipore mani-

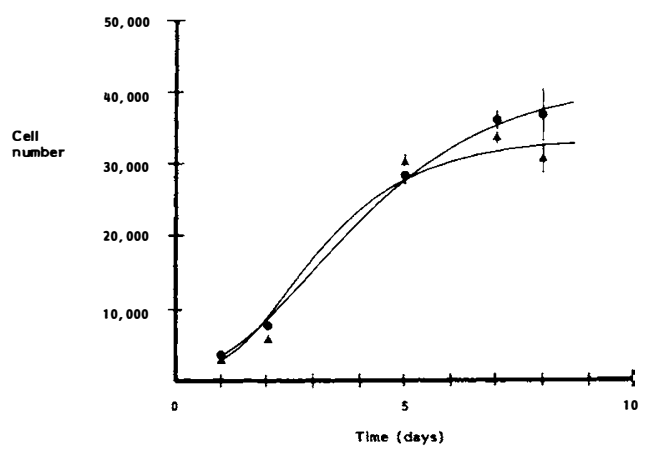

Fig. 2. The growth curve of corneal keratocytes under normal culture conditions (DMEM+1\% FCS) (circles) and in the presence of medium conditioned by corneal epithelial cells (triangles). The epithelial cell-conditioned medium (4th passage cells) did not alter the growth parameters (see Table I). The solid lines are the best fit of the Gompertz equation to the data. The cells (2nd passage) were seeded at a density of $6.6 \times 10^{3} \mathrm{ml}^{-1}$ and the plating density was assessed after 24 hours $(t=1$ on graph). This number was taken as the initial number of cells $\left(N_{o}\right)$. The points represent the mean \pm standard error $(S E)$ of triplicate cultures. fold, placed in scintillant (Packard Scintillator 229) and the radioactivity was determined in a liquid scintillation counter (Beckman). The results are expressed as the mean ( \pm standard error) less background of triplicate cultures.

\section{Terminology}

All cells used in this study were from the bovine cornea (with the exception of the mouse thymocytes). In the rest of the text we will refer to keratocytes and corneal epithelial cells without reference to the species rather than use abbreviations.

\section{Results}

\section{Effects of corneal epithelial-conditioned} medium on the growth of keratocytes

The proliferation of keratocytes followed exponential kinetics for an initial phase levelling off to a plateau at five days (Fig. 2). No effect was observed on the growth of those cells exposed to epithelial-conditioned medium compared to the control cultures. From fits of the Gompertz growth function (equation 1) to the data, neither the ratio $\mathrm{A} / \mathrm{r}$ (growth rate/retardation rate) nor the maximum population doubling levels $\left(\mathrm{PDL}_{\max }\right)$ were found to differ significantly (Table I).

\section{Effect of keratocyte-conditioned medium on} the growth of corneal epithelial cells

All experiments were performed on cells from the outer layers of the cornea. This was achieved by using a sequential digestion technique (see Materials and Methods). These cells had the typical epithelial morphology illustrated in Fig. 1a.

All epithelial cells exposed to keratocyteconditioned medium exhibited enhanced growth compared to controls (Fig. 3). An interesting and unexpected result was observed with a reduced level of FCS. Those cells exposed to conditioned medium with $1 \%$ FCS underwent a greater number of population doublings than those with 5\% FCS implying an inhibitory influence of the FCS. In both those cells grown in $1 \%$ and $5 \%$ FCS, the conditioned medium resulted in higher values 


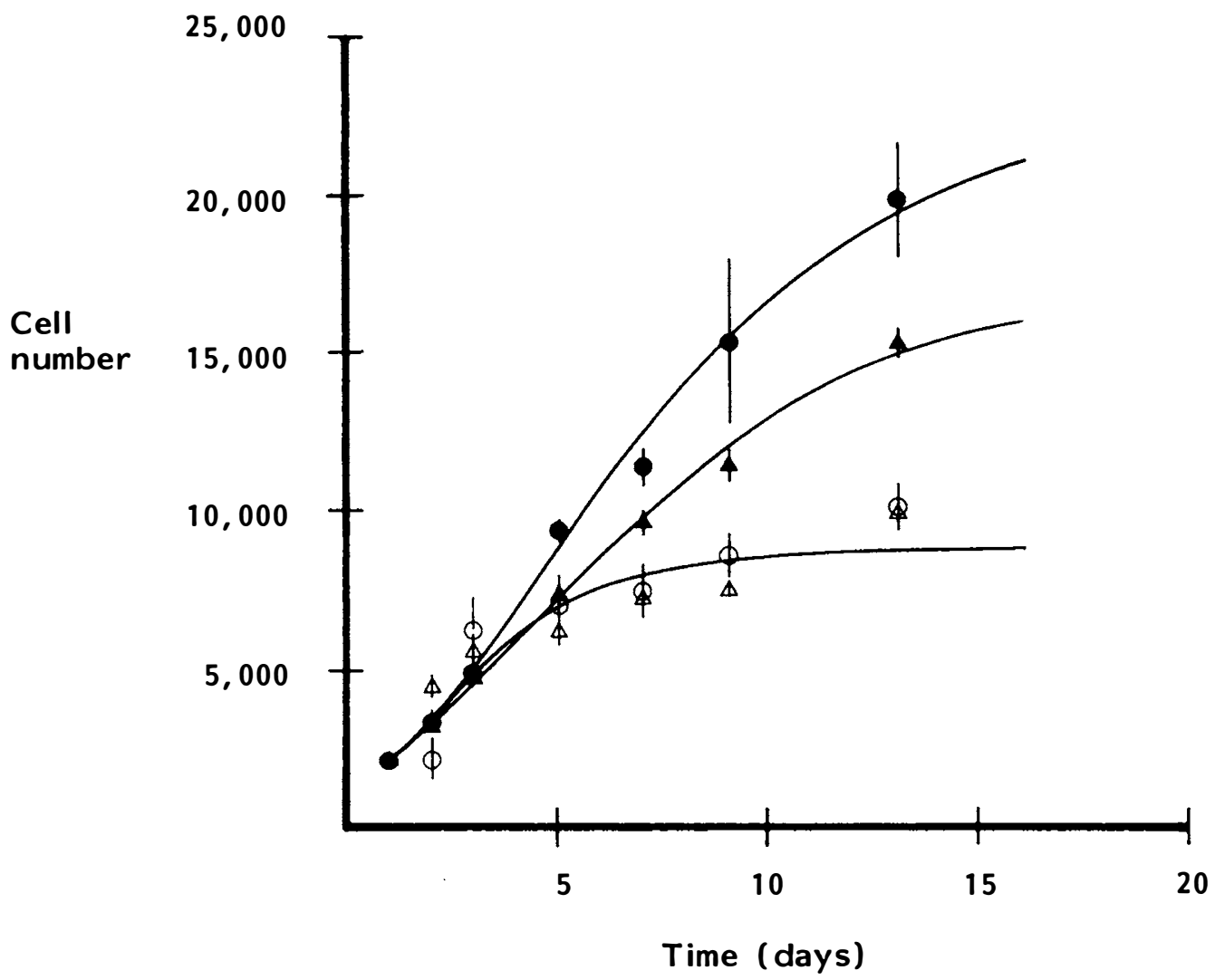

Fig. 3. The growth curves of corneal epithelial cells exposed to unconditioned medium (DMEM) with $1 \%$ FCS (open circles) and 5\% FCS (open triangles) and keratocyte-conditioned medium containing $1 \%$ FCS (filled circles) and $5 \%$ FCS (filled triangles). The cells (4th passage) were seeded at $9.2 \times 10^{4}$ cells/well of a 96 well culture plate in DMEM+10\% FCS to maximise plating. After 24 hours the cells were counted to determine the initial number of cells and the medium was changed to the test conditions. The conditioned medium was DMEM + insulin + transferrin (DMEIT) conditioned by confluent keratocytes for 5 days and mixed 50:50 with unconditioned medium with $2 \%$ and $10 \%$ FCS respectively. Each point represents the mean ( \pm SE) of triplicate cultures. The solid lines represent fits of the Gompertz equation (equation 1) to the data. The values for the growth rate and retardation rate are given in Table $\mathrm{I}$.

Table I The effect of conditioned medium on growth parameters of corneal keratocytes and epithelial cells

\begin{tabular}{lcccc}
\hline & $A$ & $r$ & $A / r$ & $P D L_{\max }$ \\
\hline Keratocytes: & & & & \\
$\quad$ Control medium & $1.35 \pm 0.23$ & $0.57 \pm 0.11$ & 2.68 & 8.92 \\
$\quad$ Conditioned medium & $1.89 \pm 0.83$ & $0.77 \pm 0.36$ & 2.46 & 8.15 \\
Epithelial cells: & & & & 4.08 \\
$\quad$ Control medium 1\% FCS & $0.68 \pm 0.17$ & $0.46 \pm 0.13$ & 1.47 & 8.10 \\
2Conditioned medium 1\% FCS & $0.55 \pm 0.04$ & $0.23 \pm 0.02$ & 2.44 & 4.93 \\
$\quad$ Control medium 5\% FCS & $0.61 \pm 0.15$ & $0.41 \pm 0.12$ & 1.48 & 7.19 \\
2Conditioned medium 5\% FCS & $0.47 \pm 0.03$ & $0.22 \pm 0.02$ & 2.17 & \\
\hline
\end{tabular}

The values of the parameters were obtained from best fits of the Gompertz Growth Function (equation 1) to the data. $\mathrm{A}=$ growth rate constant, $\mathrm{r}=$ retardation constant, $\mathrm{PDL}_{\max }=$ maximum population doubling level.

${ }^{1}$ Medium conditioned by corneal epithelial cells.

${ }^{2}$ Medium conditioned by corneal keratocytes. 


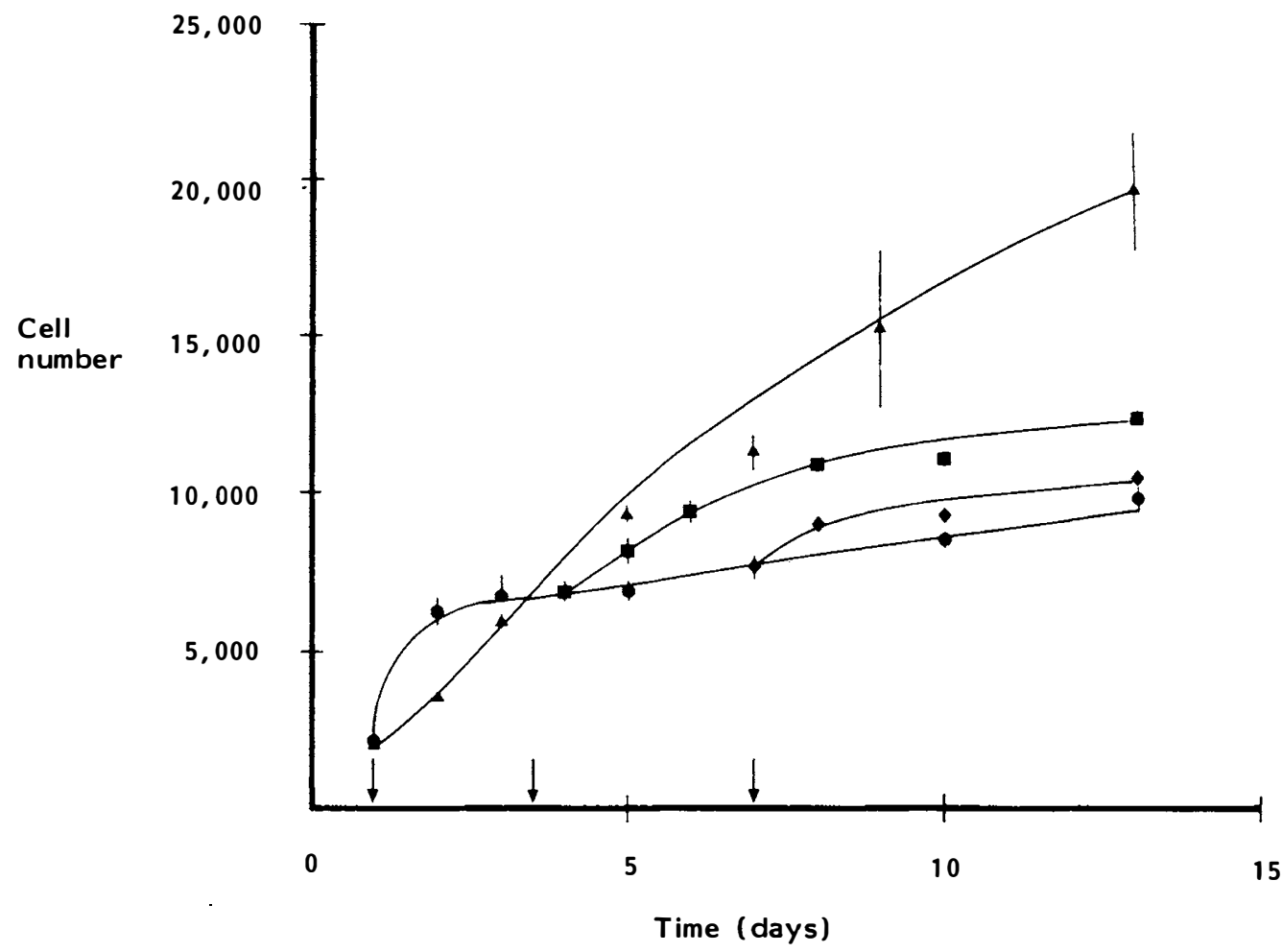

Fig. 4. The stimulation of corneal epithelial cells at different phases of the growth curve by keratocyte-conditioned medium. The cells (3rd passage) were all seeded in DMEM+1\% FCS, counted after 24 hours and re-fed with the appropriate test conditions. The control cells (circles) were grown in unconditioned medium throughout. The arrows on the time axis indicate when the keratocyte-conditioned medium (DMEIT 3 days on 2nd passage keratocytes) was added; at $t=1$ day (triangles), $t=3.5$ days (squares) and $t=7$ days (diamonds) respectively. Cells were re-fed every three days and each point represents the mean $( \pm S E)$ of triplicate cultures.

for the growth/retardation constant ratio and PDL (Table I).

Also apparent from Table $\mathrm{I}$ is the fact that, under the same conditions, keratocytes grow faster than corneal epithelial cells. The growth potential in the epithelial cells is increased to the same level as that of the keratocytes by exposure to keratocyte-conditioned medium.

\section{Stimulation at different stages of the growth curve}

Stimulation of corneal epithelial cells by keratocyte-conditioned medium was greater the earlier the stimulus was applied (Fig. 4). Thus those cells exposed to keratocyte-conditioned medium from day one achieved a higher PDL than those cells exposed at day 3.5 and day seven. Those cells exposed to the conditioned medium at day seven, close to the plateau phase, only marginally exceeded the PDL of the control cultures. In the exponential phase of the growth curve, most cells will be in the cell cycle and during this phase their growth rate can be enhanced by keratocytederived factors. At the plateau phase, cells exit from the cell cycle and are no longer amenable to stimulation.

\section{Dose response of epithelial cells to}

keratocyte-derived factor(s)

In order to determine whether the stimulatory effect of keratocyte-conditioned media was a 


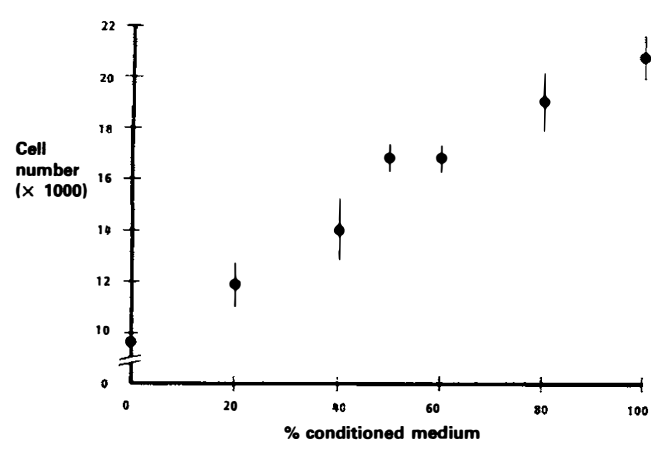

Fig. 5. Dose-response curve for the effect of keratocyte-conditioned medium on corneal epithelial cells. The cells were grown in varying proportions of unconditioned:conditioned medium from $0 \%$ to $100 \%$. Each datum point represents the mean ( $\pm S E$ ) calculated from triplicate cultures.

genuine pharmacological phenomenon, we measured the degree of stimulation over a range of dilutions of the keratocyte-conditioned medium. The resulting doseresponse curve is given in Fig. 5. Cell proliferation was measured in the absence of conditioned medium and with an increasing proportion of conditioned medium, up to $100 \%$. The linear increase in growth stimulation in response to an increasing proportion of conditioned medium confirms the pharmacological nature of the phenomenon and the lack of a plateau shows that the factor(s) responsible for the stimulation was not sufficiently concentrated, even at $100 \%$ conditioned medium, to achieve a maximum response.

\section{Thymocyte stimulation}

It has been shown previously ${ }^{3}$ that corneal epithelial cells secrete a factor, particularly when actively dividing, that stimulates the proliferation of thymocytes. This factor has been named corneal epithelial-derived thymocyte activating factor (CETAF). It is thought that this factor is secreted in conditions of stress, particularly after corneal damage, and that it is important in wound healing. Having demonstrated that corneal keratocytes secrete a factor(s) that stimulates corneal epithelial cell proliferation we wanted to know whether this factor also stimulated thymocyte proliferation. We first confirmed the findings of Grabner et $\mathrm{al}^{3}$ and Luger et $\mathrm{al}^{9}$ that corneal epithelial cells do indeed secrete a factor(s) capable of stimulating the proliferation of thymocytes (Fig. 6). The first column (A) represents the control case of no thymocyte stimulation (unconditioned medium), while those thymocytes in the second column (B) were exposed to medium that had been previously conditioned by corneal epithelial cells. These thymocytes exhibited a large and significant incorporation of labelled thymidine thereby demonstrating the mitogenic property of the epithelialderived factor(s). In contrast, keratocyteconditioned medium, which stimulated epithelial cell proliferation, failed to stimulate thymocyte proliferation (Fig. 6, column C). Thus, epithelial-derived factor (CETAF)

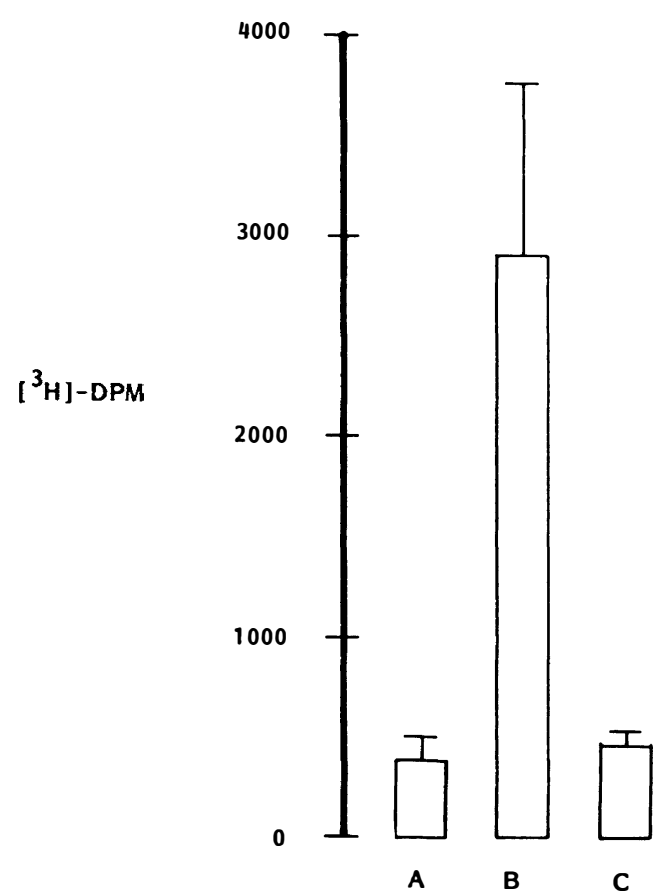

Fig. 6. Thymocyte proliferation assay. The y-axis represents the degree of incorporation of radioactivity in decays per minute (DPM). Mouse thymocytes were grown in conditions that were subthreshold for activation in all three experiments and exposed to:

(A), unconditioned medium;

(B), medium conditioned by corneal epithelial cells;

(C), medium conditioned by corneal keratocytes.

Only keratocyte-conditioned medium induced activation of proliferation. The data are given as the mean $( \pm$ $S E)$ of triplicate cultures. 
stimulated proliferation in thymocytes but not keratocytes and keratocyte factor(s) stimulates proliferation in epithelial cells but not thymocytes.

\section{Discussion}

In this study of growth control in the bovine cornea it is demonstrated that growth factor(s) secreted by keratocytes will only stimulate $G_{1}$ epithelial cells, that is, epithelial cells in the cell cycle. The stimulatory effect of this factor(s) decreases as cell proliferation decreases. The observation that those epithelial cells exposed to reduced levels of fetal calf serum (FCS) underwent a greater number of population doublings implies an inhibitory effect of FCS. This has been observed by $\mathrm{Jacob}^{7}$ in human lens epithelial cells. It can be accounted for by application of the Gompertz growth function which invokes both a growth constant and a retardation constant: a combination that allows for self-inhibitory growth regulation. The growth rate constant was indeed higher in high levels of FCS (see Table I) but so also was the retardation rate. The resultant decrease in the $\mathrm{A} / \mathrm{r}$ ratio (from 2.4 in $1 \%$ FCS to 1.5 in $5 \%$ FCS) means that the cells achieve fewer population doublings. These theoretical parameters may have real counterparts in the form of inhibitory factors. For example, these factors may be secreted at a greater rate the faster cells divide or they may be produced at a constant rate but lost by diffusion or breakdown and rapidly dividing cells would receive a greater exposure.

The mitogenic effect of keratocyte factor(s) on epithelial cells is not reciprocal, epithelialderived factors do not stimulate proliferation in keratocytes. And, while keratocytederived growth factor(s) stimulates proliferation in $G_{1}$ epithelial cells it does not stimulate thymocyte proliferation.

These results suggest that, in the process of wound healing in the cornea, epithelial cells will be stimulated to proliferate by non-proliferating keratocytes as long as they remain in $\mathrm{G}_{1}$. The keratocytes can be stationary or dividing since they produce mitogenic factors in both states. Epithelial cells will continue to divide until such time as they become contact inhibited when they will enter $G_{0}$ and leave the cell cycle. While the epithelial cells are proliferating they increase their secretion of a factor(s) that stimulates the immune response by activating thymocyte proliferation.

Thus wounding effectively lifts an inhibitory influence on the corneal epithelium rendering it amenable to mitogenic stimulation by the stormal keratocytes and setting in train a series of events that lead to wound closure and activation of the immune response.

We would like to thank Professor I. Grierson, Department of Pathology, Institute of Ophthalmology, London, for his valuable advice in setting up the corneal cell preparation.

This work was funded by the Wellcome Trust. We thank the Humane Research Trust for additional financial support.

\section{References}

${ }^{1}$ Chan KY and Hasche RH: Epithelial-stromal interactions: specific stimulation of corneal epithelial cell growth in vitro by a factor(s) from cultured stromal fibroblasts. Exp Eye Res 1983, 36: 23146.

${ }^{2}$ Crosson CE, Klyce SD, Beuerman RW: Epithelial wound closure in the rabbit cornea. Invest Ophthalmol and Vis Sci 1986, 27: 464-73.

${ }^{3}$ Grabner G, Luger TA, Smolin G, Oppenheim JJ: Corneal epithelial cell-derived thymocyte activating factor (CETAF). Invest Ophthalmol and Vis Sci 1982, 23: 757-63.

${ }^{4}$ Wright NA and Voncina D: Studies on postnatal growth of the rat adrenal cortex. J Anat 1977, 123: 147-56.

${ }^{5}$ Laird AK: Dynamics of tumor growth. Brit J Cancer 1964, 18: 490-502.

${ }^{6}$ Laird AK: Dynamics of embryonic growth. Growth 1966, 30: 263-75.

${ }^{7}$ Jacob TJC: Human lens epithelial cells in culture: a quantitative evaluation of growth rate and proliferative capacity. Exp Eye Res 1987, 45: 93-104.

${ }^{8}$ Jacob TJC, Humphry RC, Davies EG, Thompson GM: Human retinal extract stimulates the proliferation of human lens epithelial cells. Eye 1988, 2: $304-8$.

${ }^{9}$ Luger TA, Stadler BM, Katz SI, Oppenheim JJ: Epidermal cell (keratinocyte)-derived thymocyte-activating factor (ETAF). J Immunol 1981, 127: 1493-8. 